Supplement of Biogeosciences, 12, 6707-6719, 2015

http://www.biogeosciences.net/12/6707/2015/

doi:10.5194/bg-12-6707-2015-supplement

(C) Author(s) 2015. CC Attribution 3.0 License.

(c) (i)

Supplement of

\title{
Landscape-scale changes in forest canopy structure across a partially logged tropical peat swamp
}

B. M. M. Wedeux and D. A. Coomes

Correspondence to: D. A. Coomes (dac18@cam.ac.uk)

The copyright of individual parts of the supplement might differ from the CC-BY 3.0 licence. 


\section{(I) Detection of logging roads with ClasLite and estimation of logged forest cover}

\section{Detection of logging routes}

Gaveau et al. (2014) published maps of deforestation and logging for the whole of Borneo, revealing for the first time the extent of forest loss and logging over the last 40 years. Before the publication of this paper, we independently carried out a survey of logging routes development and logging extent with focus on the Mawas area. There are some differences between our approach and theirs, but our results are similar.

Gaveau et al. (2014) detected logging "roads" using Landsat MSS, TM, and ETM+ imagery with $30 \times 30$ m pixels, which was visually interpreted (data available for download at: http://gislab.cifor.cgiar.org/wm/borneo/). We used Landsat TM, ETM+ and OLI/TIRS imagery listed in Table S1. Contrary to Gaveau et al. (2014) though, prior to conducting a visual survey for logging roads we processed the Landsat imagery using CLASLite to give subpixel-level information on fraction of ground, non-photosynthetic biomass and live vegetation (Asner, 2009), following so the approach of Bryan et al. (2013). We visually supervised all images and recorded all linear human-made features. While Gaveau et al. (2014) detected logging routes in the area up to the year 2000, which marked the end of concessionary logging, we continued to map a development of logging routes beyond that year. Post-2000 logging was illegal as no concessions were granted and the area was protected as a 'conservation forest' since 2003 ('hutan konservasi' and 'hutan lindung').

Our logging-road maps obtained from the satellite imagery of 1994 to 2000 identified $395 \mathrm{~km}$ of roads that were also recorded by Gaveau et al. (2014), and $150 \mathrm{~km}$ of routes which they had missed (Fig. S1a). They found an additional $31 \mathrm{~km}$ that we had failed to spot. We combine data from Gaveau et al. (2014) and our data to create the most complete map yet available of logging routes in the Mawas area up to the year 2000. Post-2000 we detected 190 $\mathrm{km}$ of illegal logging routes. Most of them were within areas already affected by logging up to 2000 (Fig S1b). 
Table S1. Landsat images used to classify forest cover and detect logging routes.

\begin{tabular}{lllll}
\hline Path & Row & Day & Month & Year \\
\hline 118 & 61 & 08 & 07 & 1994 \\
118 & 61 & 01 & 08 & 1997 \\
118 & 61 & 16 & 07 & 2000 \\
118 & 61 & 01 & 06 & 2001 \\
118 & 61 & 27 & 01 & 2002 \\
118 & 61 & 16 & 05 & 2004 \\
118 & 61 & 07 & 02 & 2009 \\
118 & 61 & 08 & 13 & 2013 \\
118 & 61 & 09 & 30 & 2013 \\
\hline
\end{tabular}

(a) Pre-2000 concessionary logging, comparison Gaveau et al. 2014 (yellow) and this study (dashed)

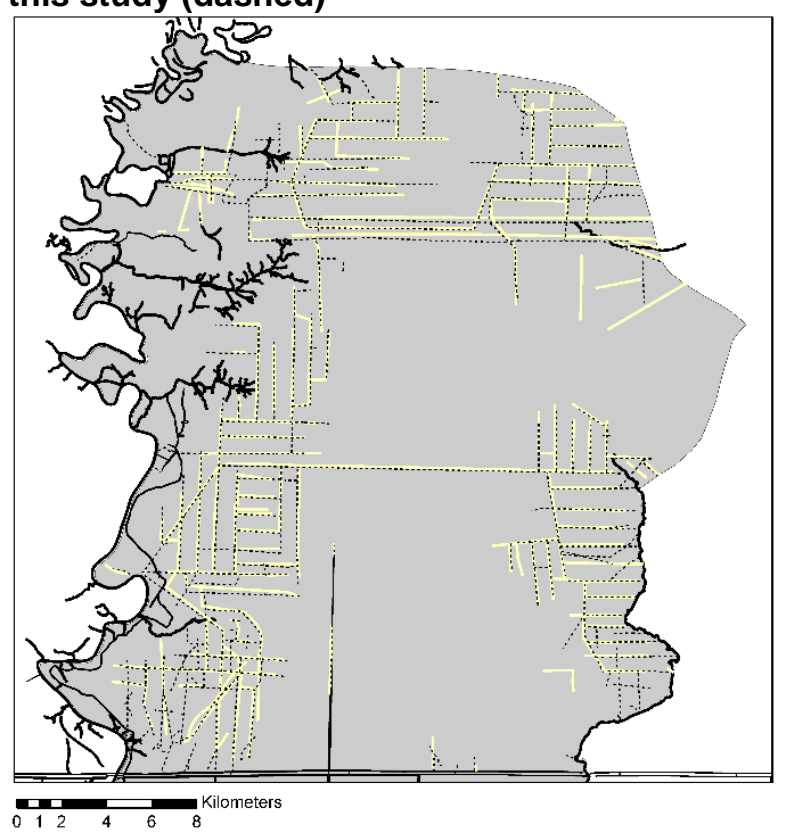

(b) Post-2000 illegal logging (red) around the existing pre-2000 logging route network (yellow)

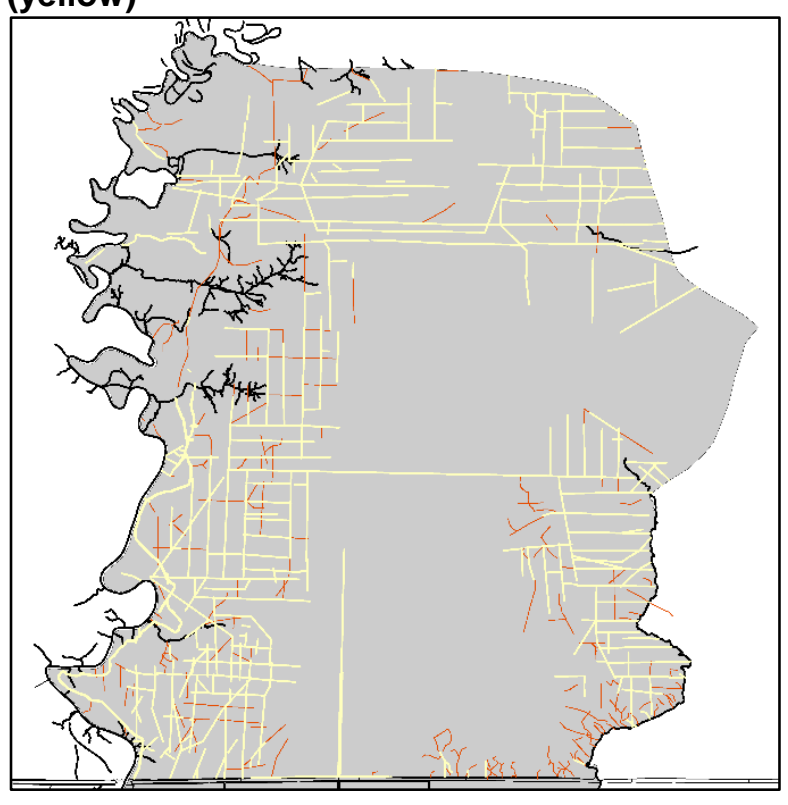

Figure S1. Logging routes in the Mawas area: (a) comparison of logging routes found by Gaveau et al. (2014) (yellow), and logging routes found by us (dashed) until the year 2000; (b) illegal expansion of illegal logging routes detected between the year 2000 and 2013 (red) around the existing pre-2000 logging route network (yellow). 


\section{Forest cover affected by logging}

CLASlite transforms Landsat imagery to a reflectance image and then applies a probabilistic spectral un-mixing model to yield sub-pixel fractional cover maps, where each pixel is characterised by fractions of photosynthetic vegetation, non-photosynthetic vegetation, and bare soil. We delineated forest cover by selecting pixels with a photosynthetic vegetation fraction $>80 \%$ and a bare soil fraction $<20 \%$, as recommended by the developers (Asner, 2009).

The width of the buffer zones used to estimate the extent of forest affected by logging routes varies among studies. Gaveau et al. (2014) chose to apply a single buffer width of 700 $\mathrm{m}$ around logging roads across the whole of Borneo to estimate the area of logged forest. Access is more difficult in peat swamp forests, however, and Franke et al. (2012) report that trees were usually removed up to $500 \mathrm{~m}$ from logging railways or routes.

To decide upon a suitable buffer around concessionary logging routes, we constructed 22 virtual $1-\mathrm{km}$ transects perpendicular to logging routes and recorded the mean height of the canopy height model (CHM) from ALS in 20-m-diameter circles at 20-m intervals along that transect. We fitted a loess-smoothing curve to the relationship between mean canopy height and distance to logging routes (Fig. S2) and observed that, in most cases, mean height is low close to the logging route and increases until stabilising at around $500 \mathrm{~m}$, and subsequently decreases again. This decrease of mean canopy height is probably linked to the underlying peat depth gradient: concessionary logging was mostly concentrated on shallow peats so peat depth increases with distance from the logging routes; these deeper peats are associated with shorter forests. From the available evidence, we argue that $500 \mathrm{~m}$ is a more suitable buffer zone for this peat swamp than the universal 700-m zone used by Gaveau et al (2014), as the larger zone includes the effects of peat depth variability as well as logging effects. Furthermore, we noted that logging routes established within the concessions were organised as grids that were mostly $1000 \mathrm{~m}$ apart and were presumably spaced so that all forests between railways could be accessed. Thus in our study, forest zones within $500 \mathrm{~m}$ of concessionary logging routes are classified as logged. 


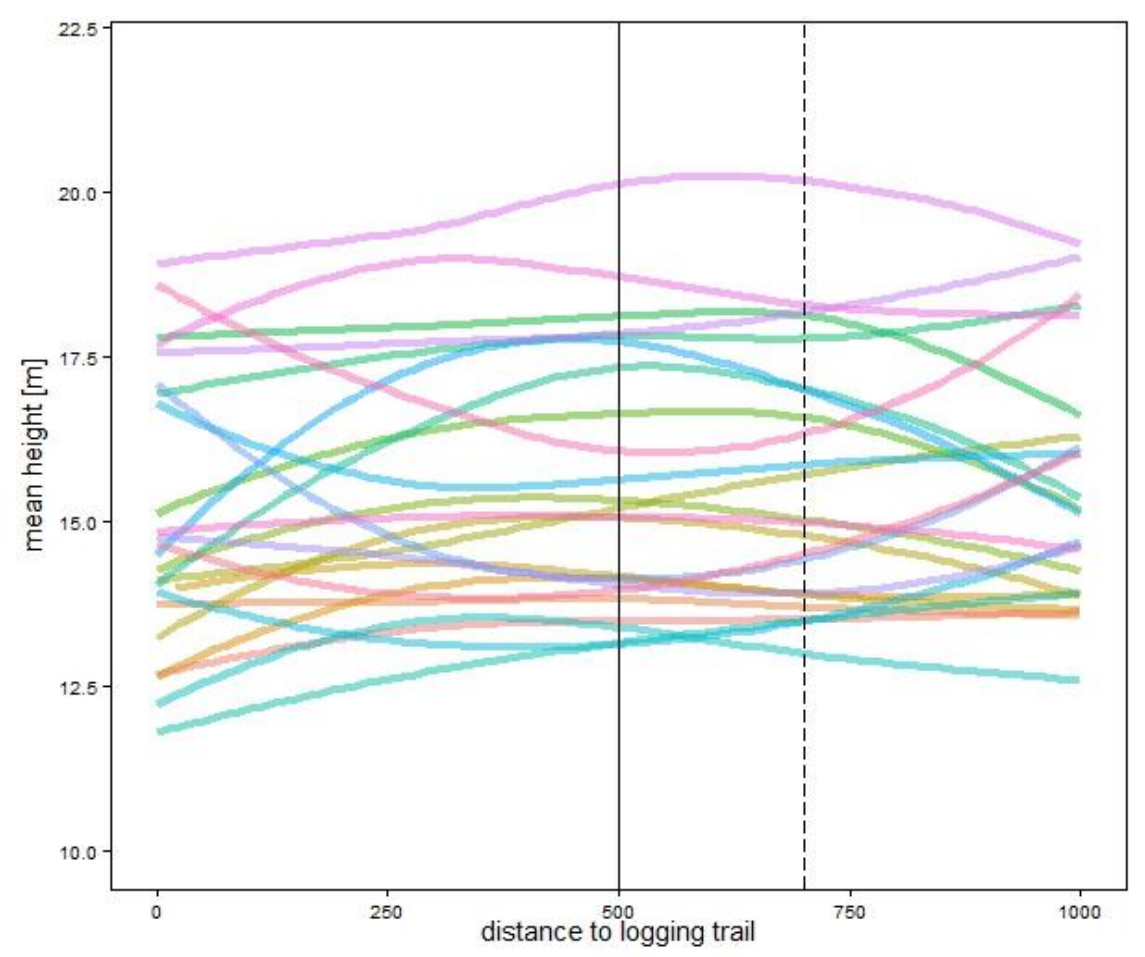

Figure S2. Mean canopy height (mean height of CHM) as measured from ALS with distance to logging roads. We interpret that the general increase in mean height between 0 to $\sim 200 \mathrm{~m}$ is due to decrease of effect of logging with distance to the logging route. The often-observed decrease in mean height after $\sim 500 \mathrm{~m}$ (hard line) away from logging routes is probably due to natural variation in peat swamp forest height with peat depth. Gaveau et al. (2014) used a 700 $\mathrm{m}$ buffer around logging roads (dashed line) which we deem too broad here as it encompass logging effects as well as environmental effects on mean canopy height.

\section{(II) Comparison of the left-truncated pareto and the finite left-truncated pareto}

Canopy gap size frequency distributions have traditionally been described by the pareto distribution, but these have 'fat tails' which can lead to an overestimation of very large events (Schoenberg and Patel, 2012). We used a finite power law consisting of a power law and an exponential term. The distribution function is given as:

$$
F(x)=1-\left(\frac{x_{\min }}{x}\right)^{\gamma} \times \exp \left(\frac{x_{\min }-x}{\theta}\right)
$$

where $\mathrm{x}_{\min }$ is the lower truncation point, $\gamma$ the scaling parameter of the pareto term and $\theta$ the transition parameter. $\theta$ influences the rate of the exponential and influences the zone of the transition from the pareto to exponential (Schoenberg \& Patel 2012). When $\theta>>\left(x_{\min }-x\right)$, 
$\exp \left(\frac{x_{\min }-x}{\theta}\right) \rightarrow 0$ and $F(x) \rightarrow 1-\left(\frac{x_{\min }}{x}\right)^{\gamma}$ which is akin to the left-truncated pareto distribution.

When $\mathrm{x}$ is similar or larger than the tapering parameter $\theta, \mathrm{x} \sim \theta$, then the term $\left(\frac{x_{\min }}{x}\right)^{\alpha}$ changes less rapidly than $\exp \left(\frac{x_{\min }-x}{\theta}\right)$ with increasing $\mathrm{x}$, and $F(x) \rightarrow 1-$ $\exp \left(\frac{x_{\min }-x}{\theta}\right)$ which rapidly goes to zero.

The left-truncated pareto is given by the cumulative distribution function:

$$
F(x)=1-\left(\frac{x_{\min }}{x}\right)^{\alpha}
$$

where $x_{\min }$ is the lower truncation point, here the smallest gap size considered $\left(9 \mathrm{~m}^{2}\right)$, and $\alpha$ is the scaling parameter. We differentiate it to give the probability distribution function:

$$
f(x)=\gamma \times x_{\min }^{\alpha} \times x^{-\alpha-1}
$$

On a log-log scale, this function gives a straight line:

$$
\log (p)=\log \left(\alpha \times x_{\min }{ }^{\alpha}\right)-(\alpha+1) \times \log (x),
$$

where the first term is a constant and $\alpha+1$ is the slope of the power law.

The scaling exponent of the pareto distribution that we used corresponds thus to $[\alpha+1]$. In order to make this scaling exponent comparable to the scaling exponents reported in other studies (Asner et al., 2013; Kellner and Asner, 2009), we need to sum 1 to the estimated parameter $\gamma$. We report $\alpha=\gamma+1$.

\section{(III) RSTAN code to fit a tapered pareto distribution to gap sizes and model convergence}

The $\mathrm{R}$ code used to fit a tapered left-truncated pareto distribution to gap sizes by Bayesian inference and using the package RStan is reproduced below. We used a normally distributed prior with a mean of 1 and a standard deviation of 1 for the scaling parameter $\alpha$ and a normally distributed prior with a mean of 0.01 and a standard deviation of 0.5 for the inverse of the tapering point $\theta$ (the tapering point is large, hence its inverse is close to 0 ). We ran three chains with a burn-in phase of 2000 iterations and a sampling phase of 3000 iterations and saved each second iteration to generate the posterior distribution. 
\#\#STAN model to fit a tapered left-truncated pareto distribution to gap sizes

\#\# the parameters are fitted at plot level

\#load RSTAN library

library(rstan)

\#load the data: the data should contain 1 column informing the plot ID (here: plotID) and a column informing \#the sizes of gaps (here: area)

data=read.csv(\#\#\#)

\#define the STAN model

gapmodel <- "

data \{

int $<$ lower $=0>\mathrm{N}$;

//number of observations

int $<$ lower $=0>$ Nplot;

$/ /$ number of plots

vector $<$ lower $=0>[\mathrm{N}]$ tgaparea;

//the gap size data

vector $\langle$ lower $=0\rangle[\mathrm{N}]$ invtgaparea;

//the inverse of the gap size data (= 1/tgaparea, calculated in $\mathrm{R})$

real $<$ lower $=0>\mathrm{b}$;

int $<$ lower $=0>\operatorname{plot}[\mathrm{N}]$;

//left-truncation point

\}

parameters \{

real $<$ lower $=0>$ a $[$ Nplot $]$;

real $<$ lower $=0>$ invt $[\mathrm{Nplot}]$;

\}

model \{

real a1[N];

real invt $1[\mathrm{~N}]$;

for (i in $1: N)\{$

a1[i] <- a[plot[i]];

invt1[i] <- invt[plot[i]];

\}

a normal(\#\#\#,\#\#\#);

invt normal(\#\#\#,\#\#);

$/ /$ prior for a

$/ /$ prior for invt

//the $\log$-likelihood is $\log (a / x+t)+a * \log (b / x)+(b-x) * t$ where $b$ is lower truncation point, $a$ is the shape parameter and invt is the inverse of the location of the taper

for (i in $1: \mathrm{N})$

increment_log_prob(log $((a 1[i] *$ invtgaparea[i] $)+$ invt1[i] $)+a 1[i] * \log (b * i n v t g a p a r e a[i])+(b-$

tgaparea[i])*invt1[i]) ;

\}"

\#define where to take the data from

STANdata $<-$ list $(\mathrm{N}=$ length (data\$area),

\#number of observed gaps

Nplot = length(unique (data\$plotID)), \#number of plots

tgaparea $=$ data $\$$ area

invtgaparea $=1 /$ tgaparea

plot $=$ as.numeric (data\$plotID), \#numeric plot index

$\mathrm{b}=\# \# \#)$

\#left truncation, to be set according to data

fit_model <- stan(model_code = gapmodel,

data $=$ STANdata,

pars $=$ NA,

chains $=\# \#$,

iter $=\# \#$,

warmup $=\# \#$,

thin $=\# \#$,

refresh $=\# \#$, 
diagnostic_file=paste('\#\#\#'),

sample_file=paste('\#\#\#'))

\#extract fitted parameter values

$\mathrm{r}<-$ as.data.frame(summary(fit_model, pars=c("a", "invt","lp__")))

\#plot the fit of the model

plot(fit_model)

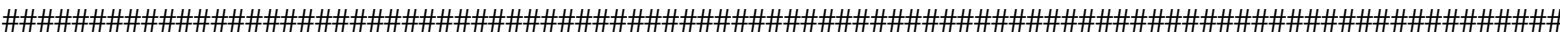

\section{Model convergence}

We visually inspected the chain traces to ensure good mixing of posterior distributions and visually ensured stabilization of the log-likelihood within the burn-in phase. For each posterior sample, the potential scale reduction factor $\hat{R}$ was provided in the RStan output. This factor indicates the extent to which the confidence intervals around a parameter could be reduced if the model was run infinitely. All $\hat{R}$ values were 1 (and hence smaller than the prescribed threshold of 1.1), indicating that the model had successfully converged and the three chains had mixed (Gelman and Hill, 2007). Finally, the effective number of simulation draws reported as $\mathrm{n}_{\text {eff }}$ in the RStan diagnostic output was always well above 100, indicating independence of simulation draws (Gelman and Hill, 2007).

\section{(IV) Predicting peat depth for plots}

We used relationships between canopy top height $\left(99^{\text {th }}\right.$ quantile), peat depth and distance to rivers to predict peat depth for plots where this information was missing. A total of 327 peat depth measurements were available for the research area. Peat depth was measured by inserting an auger into the soft peat until hitting the harder clay subsoil (KFCP, unpublished data). We calculated canopy top height in a circular neighbourhood with a $100 \mathrm{~m}$ radius around each peat depth measurement. To achieve this, we extracted the value of 10,000 random pixels $\left(1 \mathrm{~m}^{2}\right)$ of the ALS-derived canopy height model within the given neighbourhood. We used the $99^{\text {th }}$ quantile (H99) that represented the height of the 100 highest pixels, corresponding to the tallest trees. Furthermore, we measured the distance to the closest river (Kapuas river bordered by shallow peat in the west and Mantangai river bordered by deep peat in the east) from each peat depth point. Peat depth measurement points and associated top canopy height were classified as logged if they fell within $500 \mathrm{~m}$ of a logging route (see section (I) in supplement). 
We first tested for the effect of logging on canopy top height (H99) in this independent dataset. We fitted the linear model $\mathrm{H} 99=\mathrm{a}+\mathrm{b} \times$ peat depth and tested for $\mathrm{a}$ possible effect of logging by either adding logging as a factor (yes, no) or testing for the interaction between logging and peat depth. No significant logging effect is detected and the simple linear model gives $\mathrm{H} 99=34.9-1.0 \times$ peat depth with $\mathrm{R}^{2}=0.77$. The absence of logging effect can be explained by the fact that selective logging does not remove all large trees. Since logging does not significantly affect H99, H99 can be safely used to predict peat depth across the peat dome.

Peat depth was overall well predicted by H99 (peat depth $=28.0-0.8 \times H 99, \mathrm{R}^{2}=0.77$, Fig. S3a), except on shallow peat $(<4 \mathrm{~m}$; Fig. S3a) close to the Kapuas river. There in turn, the relationship between peat depth and distance to river was well-defined (peat depth $=$ $0.31+0.002 \times$ distance to Kapuas river $(\mathrm{km}), \mathrm{R}^{2}=0.59$, Fig. S3b).

For our $1 \mathrm{~km}^{2}$ sampling plots (Section 2.2 in main text), we predicted their peat depth based on distance to river if plots were within $3000 \mathrm{~m}$ of the Kapuas river. Else, we predicted plot peat depth based on canopy top height. This yielded a fit going through the origin and with an $\mathrm{R}^{2}=0.88$ between predicted and measured peat values in the 33 plots where those were available.

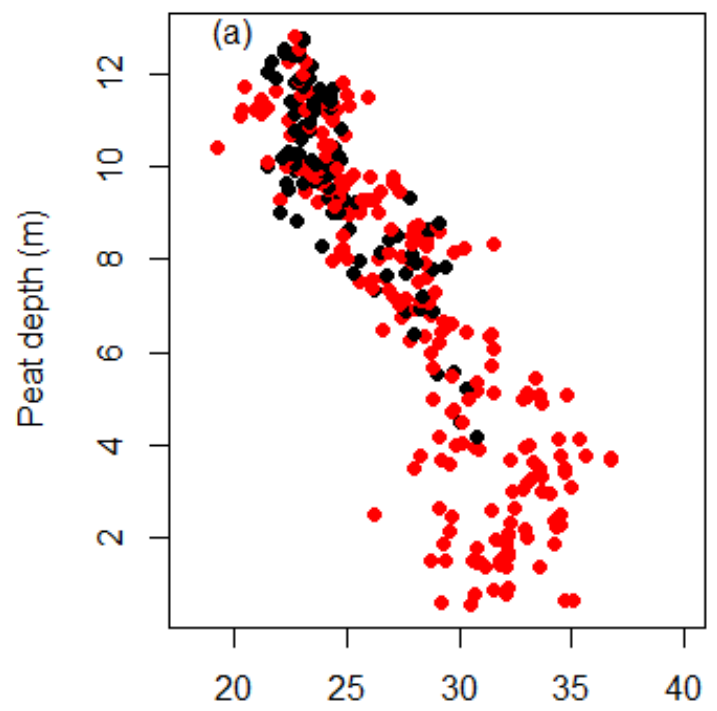

Canopy top height $(\mathrm{m})$

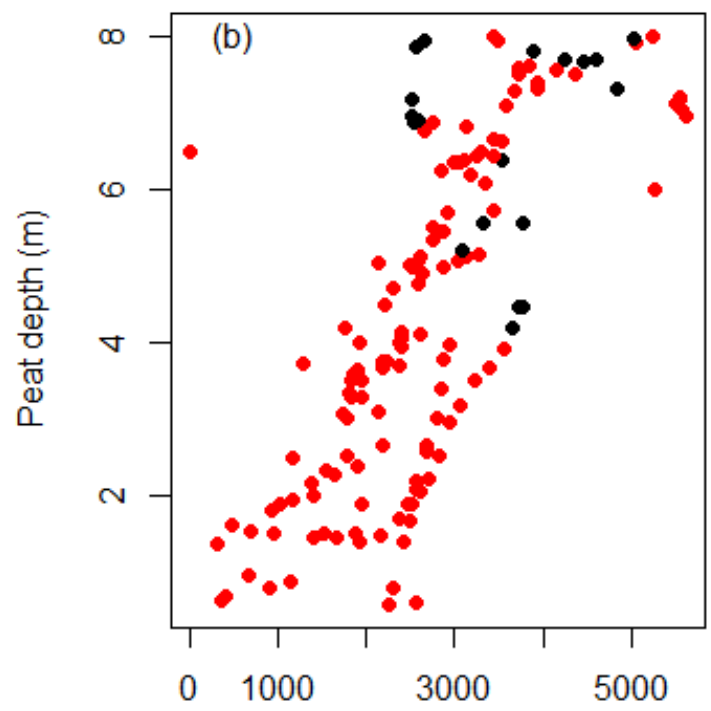

Distance to river $(\mathrm{m})$

Figure S3. Relationships between peat depth, canopy top height, and distance to rivers across the Mawas peat dome: (a) relationship between canopy top height ( $99^{\text {th }}$ quantile) and peat depth across the whole peat dome and (b) increase in peat depth with distance to the Kapuas 
river adjacent to shallow peat. Plots affected by logging are in red, while old-growth plots are in black.

\section{(V) Impact of logging pressure on canopy structure}

The logging pressure indices were devised to test for potential differences in the level of logging impact in different logged plots. Since no logging records were available, logging pressure was approximated by the density of logging routes as detected by satellite imagery. We used the Line Density tool in the ArcMap 10.2 Spatial Analyst library (ESRI, 2013) to create rasters of the density of new logging routes $\left(\mathrm{km} \mathrm{km}^{-2}\right)$ in the years 2000, 2009 and 2013 and of the cumulative density of all logging routes up to the year 2013. A pixel's logging route density was determined by the total length of logging routes within a circular neighbourhood with a radius of $500 \mathrm{~m}$. We then calculated an average new, or cumulative, logging route density value per plot using the Zonal Statistics tool in the same library. The cumulative LPI weighted all logging routes equally. The 'logging pressure index' LPI for new logging routes for each logged plot was calculated as:

$$
L P I=\operatorname{dens}_{2000} \cdot w_{2000}+\operatorname{dens}_{2009} \cdot w_{2009}+\operatorname{dens}_{2013} \cdot w_{2013},
$$

where dens is the density of new logging routes for respective years. A weight $w$ is given to that density according to logging route age. We tested different sets of weights $\left(\mathrm{w}_{2000}=1\right.$, $\left.\mathrm{w}_{2009}=10, \mathrm{w}_{2013}=14 ; \mathrm{w}_{2000}=1, \mathrm{w}_{2009}=10, \mathrm{w}_{2013}=24, \mathrm{w}_{2000}=5, \mathrm{w}_{2009}=10, \mathrm{w}_{2013}=24\right)$ giving more or less importance to old and recent logging routes. The density of old logging routes always received a smaller weight than the density of newer logging routes, as we assumed that forest recovery was greater and logging impact was smaller along older routes. 


\section{Supplementary tables}

Table S2. Airborne laser scanning (ALS) acquisition specifications. For further technical details refer to Ballhorn et al. (2014).

\begin{tabular}{ll}
\hline Laser pulse frequency & $100 \mathrm{KHz}$ \\
Scan frequency & 45 \\
Half scan angle & $22^{\circ}$ \\
Flying height & $800 \mathrm{~m}$ above-ground \\
Speed & $110 \mathrm{knots}$ \\
Side overlap & $30 \%$ \\
Net swath width & $450 \mathrm{~m}$ \\
Calculated pulse density & $2.8 \mathrm{pts} / \mathrm{m}^{2}$ \\
\hline
\end{tabular}


Table S3. Parameter values (with SEM) of the most parsimonious models selected to describe changes of canopy height and gap metrics with peat depth (peat ${ }_{M}$ ) and with logging (logg) for plots on 6-12 m deep peat. For gap metrics we give the parameters estimated for each crosssection CS (2-12 $\mathrm{m}$ for mean gap area and gap fraction; respectively 5-12 $\mathrm{m}$ for $\alpha$ and $\theta)$ going up into the vertical forest profile. We report the model with lowest AICc, except in cases where two models had similar fits (i.e. $\Delta$ AICc $<2$ ), in which cases we favoured the simpler model. *: $\mathrm{p}$ $<0.05, * *: \mathrm{p}<0.01, * * * \mathrm{p}<0.001$, n.s. $=$ non-significant.

\begin{tabular}{|c|c|c|c|c|c|c|c|c|c|c|}
\hline Canopy structure metrics & $\mathrm{CS}$ & $\operatorname{model}^{\dagger}$ & $\mathrm{a}$ & & $\mathrm{b}$ & & $\mathrm{c}$ & & \multirow{2}{*}{\multicolumn{2}{|c|}{$\mathrm{d}$}} \\
\hline \multicolumn{9}{|l|}{ Height } & & \\
\hline logit(canopy shape) & - & $a+b \cdot$ peat $_{M}+c \cdot \operatorname{logg}$ & $0.39(0.07)$ & $* * *$ & $-0.02(0.02)$ & n.s. & $-0.30(0.07)$ & $* * *$ & & \\
\hline \multicolumn{11}{|l|}{ Gaps } \\
\hline \multirow[t]{11}{*}{$\log ($ mean gap area $)$} & $2 \mathrm{~m}$ & $a+b \cdot$ peat $_{M}$ & $2.78(0.06)$ & $* * *$ & $-0.02(0.02)$ & n.s. & & & & \\
\hline & $3 \mathrm{~m}$ & $a+b \cdot$ peat $_{M}$ & $2.90(0.04)$ & $* * *$ & $-0.03(0.01)$ & $*$ & & & & \\
\hline & $4 \mathrm{~m}$ & $a+b \cdot$ peat $_{M}$ & $2.98(0.04)$ & $* * *$ & $-0.03(0.01)$ & $* * *$ & & & & \\
\hline & $5 \mathrm{~m}$ & $a+b \cdot$ peat $_{M}+c \cdot \operatorname{logg}$ & $3.03(0.03)$ & $* * *$ & $-0.05(0.01)$ & $* * *$ & $0.06(0.03)$ & $*$ & & \\
\hline & $6 \mathrm{~m}$ & $a+b \cdot$ peat $_{M}+c \cdot \operatorname{logg}$ & $3.10(0.03)$ & $* * *$ & $-0.06(0.03)$ & $* * *$ & $0.07(0.03)$ & $*$ & & \\
\hline & $7 \mathrm{~m}$ & $a+b \cdot$ peat $_{M}+c \cdot \operatorname{logg}$ & $3.19(0.04)$ & $* * *$ & $-0.08(0.01)$ & $* * *$ & $0.10(0.03)$ & $* *$ & & \\
\hline & $8 \mathrm{~m}$ & $a+b \cdot$ peat $_{M}+c \cdot \log g+d \cdot$ peat:logg & $3.35(0.06)$ & $* * *$ & $-0.11(0.01)$ & $* * *$ & $-0.05(0.09)$ & n.s. & $0.07(0.02)$ & $* *$ \\
\hline & $9 \mathrm{~m}$ & $a+b \cdot$ peat $_{M}+c \cdot \log g+d \cdot$ peat:logg & $3.49(0.07)$ & $* * *$ & $-0.10(0.02)$ & $* * *$ & $-0.07(0.12)$ & n.s. & $0.10(0.3)$ & $* *$ \\
\hline & $10 \mathrm{~m}$ & $a+b \cdot$ peat $_{M}+c \cdot \log g+d \cdot$ peat:logg & $3.63(0.10)$ & $* * *$ & $-0.11(0.03)$ & $* * *$ & $-0.05(0.16)$ & n.s. & $0.12(0.04)$ & $* *$ \\
\hline & $11 \mathrm{~m}$ & $a+b \cdot$ peat $_{M}+c \cdot \log g+d \cdot$ peat:logg & $3.79(0.13)$ & $* * *$ & $-0.08(0.04)$ & $*$ & $-0.01(0.21)$ & n.s. & $0.14(0.06)$ & $*$ \\
\hline & $12 \mathrm{~m}$ & $a+b \cdot$ peat $_{M}+c \cdot \operatorname{logg}$ & $3.73(0.15)$ & $* * *$ & $0.05(0.04)$ & n.s. & $0.61(0.14)$ & $* * *$ & & \\
\hline \multirow[t]{10}{*}{ logit(gap fraction) } & $2 \mathrm{~m}$ & $a+b \cdot$ peat $_{M}$ & $-6.41(0.28)$ & $* * *$ & $-0.56(0.07)$ & $* * *$ & & & & \\
\hline & $3 \mathrm{~m}$ & $a+b \cdot$ peat $_{M}$ & $-5.58(0.25)$ & $* * *$ & $-0.54(0.07)$ & $* * *$ & & & & \\
\hline & $5 \mathrm{~m}$ & $a+b \cdot$ peat $_{M}+c \cdot \operatorname{logg}$ & $-4.56(0.25)$ & $* * *$ & $-0.50(0.06)$ & $* * *$ & $0.45(0.23)$ & n.s. & & \\
\hline & $6 \mathrm{~m}$ & $a+b \cdot$ peat $_{M}+c \cdot \operatorname{logg}$ & $-4.09(0.25)$ & $* * *$ & $-0.44(0.06)$ & $* * *$ & $0.48(0.23)$ & $*$ & & \\
\hline & $7 \mathrm{~m}$ & $a+b \cdot$ peat $_{M}+c \cdot \operatorname{logg}$ & $-3.70(0.23)$ & $* * *$ & $-0.35(0.06)$ & $* * *$ & $0.52(0.22)$ & $*$ & & \\
\hline & $8 \mathrm{~m}$ & $a+b \cdot$ peat $_{M}+c \cdot \log g+d \cdot$ peat:logg & $-3.04(0.25)$ & $* * *$ & $-0.33(0.07)$ & $* * *$ & $-0.21(0.41)$ & n.s. & $0.23(0.11)$ & $*$ \\
\hline & $9 \mathrm{~m}$ & $a+b \cdot$ peat $_{M}+c \cdot \log g+d \cdot$ peat:logg & $-2.70(0.24)$ & $* * *$ & $-0.21(0.06)$ & $* * *$ & $-0.17(0.38)$ & n.s. & $0.21(0.10)$ & $*$ \\
\hline & $10 \mathrm{~m}$ & $a+b \cdot$ peat $_{M}+c \cdot \operatorname{logg}$ & $-2.60(0.19)$ & $* * *$ & $-0.03(0.05)$ & $* * *$ & $-0.12(0.32)$ & n.s. & & \\
\hline & $11 \mathrm{~m}$ & $a+b \cdot$ peat $_{M}+c \cdot \operatorname{logg}$ & $-2.25(0.17)$ & $* * *$ & $0.05(0.04)$ & n.s. & $0.45(0.16)$ & $* *$ & & \\
\hline & $12 \mathrm{~m}$ & $a+b \cdot$ peat $_{M}+c \cdot \log g$ & $-1.91(0.16)$ & $* * *$ & $0.13(0.04)$ & $* *$ & $0.43(0.15)$ & $* *$ & & \\
\hline$\alpha$ & $5 \mathrm{~m}$ & $a+b \cdot$ peat $_{M}$ & $2.31(0.08)$ & $* * *$ & $0.04(0.02)$ & n.s. & & & & \\
\hline
\end{tabular}




\begin{tabular}{|c|c|c|c|c|c|c|c|c|c|c|}
\hline Canopy structure metrics & $\mathrm{CS}$ & model $^{\dagger}$ & $\mathrm{a}$ & & $\mathrm{b}$ & & $\mathrm{c}$ & & $\mathrm{d}$ & \\
\hline \multirow[t]{15}{*}{ Ts } & $6 \mathrm{~m}$ & $a+b \cdot$ peat $_{M}$ & $2.28(0.07)$ & $* * *$ & $0.07(0.02)$ & $* * *$ & & & \multirow{7}{*}{$\begin{array}{l}-0.12(0.4) \\
-0.10(0.03) \\
-0.06(0.03)\end{array}$} & \multirow{7}{*}{$\begin{array}{l}* * \\
* * \\
*\end{array}$} \\
\hline & $7 \mathrm{~m}$ & $a+b \cdot$ peat $_{M}+c \cdot \operatorname{logg}$ & $2.14(0.08)$ & $* * *$ & $0.15(0.02)$ & $* * *$ & $-0.16(0.07)$ & $*$ & & \\
\hline & $8 \mathrm{~m}$ & $a+b \cdot$ peat $_{M}+c \cdot \log g+d \cdot$ peat: $\log g$ & $1.97(0.10)$ & $* * *$ & $0.19(0.03)$ & $* * *$ & $0.09(0.16)$ & n.s. & & \\
\hline & $9 \mathrm{~m}$ & $\mathrm{a}+\mathrm{b} \cdot$ peat $_{\mathrm{M}}+\mathrm{c} \cdot \log \mathrm{g}+\mathrm{d} \cdot$ peat: $\log g$ & $1.94(0.07)$ & $* * *$ & $0.15(0.02)$ & $* * *$ & $0.08(0.12)$ & n.s. & & \\
\hline & $10 \mathrm{~m}$ & $\mathrm{a}+\mathrm{b} \cdot$ peat $_{\mathrm{M}}+\mathrm{c} \cdot \operatorname{logg}+\mathrm{d} \cdot$ peat: $\log g$ & $1.92(0.06)$ & $* * *$ & $0.10(0.02)$ & $* * *$ & $0.00(0.10)$ & n.s. & & \\
\hline & $11 \mathrm{~m}$ & $\mathrm{a}+\mathrm{b} \cdot$ peat $_{\mathrm{M}}+\mathrm{c} \cdot \operatorname{logg}$ & $1.93(0.05)$ & $* * *$ & $0.04(0.01)$ & $* * *$ & $-0.12(0.04)$ & $* *$ & & \\
\hline & $12 \mathrm{~m}$ & $a+b \cdot$ peat $_{M}+c \cdot \operatorname{logg}$ & $1.85(0.03)$ & $* * *$ & $0.02(0.01)$ & $* *$ & $-0.04(0.03)$ & n.s & & \\
\hline & $5 \mathrm{~m}$ & $a+b \cdot$ peat $_{M}+c \cdot \operatorname{logg}$ & $99.7(18.9)$ & $* * *$ & $-16.4(4.7)$ & $* * *$ & $47.1(17.9)$ & $* *$ & & \\
\hline & $6 \mathrm{~m}$ & $a+b \cdot$ peat $_{M}+c \cdot \operatorname{logg}$ & $121.4(20.0)$ & $* * *$ & $-16.6(4.2)$ & $* * *$ & $35.7(15.8)$ & $*$ & & \\
\hline & $7 \mathrm{~m}$ & $a+b \cdot$ peat $_{M}$ & $122.5(15.8)$ & $* * *$ & $-9.5(4.2)$ & $*$ & & & & \\
\hline & $8 \mathrm{~m}$ & $a+b \cdot$ peat $_{M}$ & $132.7(23.5)$ & $* * *$ & $-2.6(6.3)$ & n.s. & & & & \\
\hline & $9 \mathrm{~m}$ & $a+b \cdot$ peat $_{M}$ & 242.7 (136.9) & n.s. & $-2.0(36.5)$ & n.s. & & & & \\
\hline & $10 \mathrm{~m}$ & $a+b \cdot$ peat $_{M}$ & $922.0(1016.9)$ & n.s. & $-15.2(271.2)$ & n.s. & & & & \\
\hline & $11 \mathrm{~m}$ & $a+b \cdot$ peat $_{M}+c \cdot \log g$ & $2765.9(3739.0)$ & n.s. & $285.3(997.3)$ & n.s. & $-579.7(3863.1)$ & n.s. & & \\
\hline & $12 \mathrm{~m}$ & $a+b \cdot$ peat $_{M}+c \cdot \operatorname{logg}$ & $-6845.9(8698.2)$ & n.s. & $2673.6(2163.1)$ & n.s. & $28922(8072.2)$ & $* * *$ & & \\
\hline
\end{tabular}

$\ddagger$ peat $_{M}=$ peat depth -6 
Table S4. Parameter values (with SEM) of models describing changes of canopy height and gap metrics with peat depth (peat) for plots on 0-5 m deep peat where no comparison between old-growth and logged forest could be done. $*$ : p < 0.05, **: p < 0.01, *** p < 0.001, n.s. $=$ non-significant.

\begin{tabular}{|c|c|c|c|c|c|c|}
\hline \multirow{2}{*}{$\begin{array}{l}\text { Canopy structure metrics } \\
\text { Height }\end{array}$} & \multirow[t]{2}{*}{$\mathrm{CS}$} & \multirow[t]{2}{*}{ model } & \multicolumn{2}{|l|}{$\mathrm{a}$} & \multicolumn{2}{|l|}{$\mathrm{b}$} \\
\hline & & & & & & \\
\hline logit(canopy shape) & - & $a+b \cdot$ peat & $-0.27(0.08)$ & $* * *$ & $-0.02(0.02)$ & n.s. \\
\hline \multicolumn{7}{|l|}{ Gaps } \\
\hline \multirow[t]{11}{*}{$\log ($ mean gap area $)$} & $2 \mathrm{~m}$ & $a+b \cdot$ peat & $2.97(0.07)$ & $* * *$ & $-0.02(0.02)$ & n.s. \\
\hline & $3 \mathrm{~m}$ & $a+b \cdot$ peat & $3.06(0.07)$ & $* * *$ & $-0.02(0.02)$ & n.s. \\
\hline & $4 \mathrm{~m}$ & $a+b \cdot$ peat & $3.15(0.06)$ & $* * *$ & $-0.02(0.02)$ & n.s. \\
\hline & $5 \mathrm{~m}$ & $a+b \cdot$ peat & $3.23(0.06)$ & $* * *$ & $-0.03(0.02)$ & n.s. \\
\hline & $6 \mathrm{~m}$ & $a+b \cdot$ peat & $3.28(0.06)$ & $* * *$ & $-0.02(0.02)$ & n.s. \\
\hline & $7 \mathrm{~m}$ & $a+b \cdot$ peat & $3.37(0.06)$ & $* * *$ & $-0.03(0.02)$ & n.s. \\
\hline & $8 \mathrm{~m}$ & $a+b \cdot$ peat & $3.47(0.07)$ & $* * *$ & $-0.04(0.02)$ & n.s. \\
\hline & $9 \mathrm{~m}$ & $a+b \cdot$ peat & $3.59(0.08)$ & $* * *$ & $-0.04(0.02)$ & n.s. \\
\hline & $10 \mathrm{~m}$ & $a+b \cdot$ peat & $3.75(0.09)$ & $* * *$ & $-0.05(0.02)$ & n.s. \\
\hline & $11 \mathrm{~m}$ & $a+b \cdot$ peat & $3.94(0.11)$ & $* * *$ & $-0.05(0.03)$ & n.s. \\
\hline & $12 \mathrm{~m}$ & $a+b \cdot$ peat & $4.22(0.14)$ & $* * *$ & $-0.05(0.04)$ & n.s. \\
\hline \multirow[t]{11}{*}{ logit(gap fraction) } & $2 \mathrm{~m}$ & $a+b \cdot$ peat & $-6.17(0.26)$ & $* * *$ & $-0.08(0.08)$ & n.s. \\
\hline & $3 \mathrm{~m}$ & $a+b \cdot$ peat & $-5.46(0.24)$ & $* * *$ & $-0.08(0.07)$ & n.s. \\
\hline & $4 \mathrm{~m}$ & $a+b \cdot$ peat & $-4.91(0.22)$ & $* * *$ & $-0.07(0.07)$ & n.s. \\
\hline & $5 \mathrm{~m}$ & $a+b \cdot$ peat & $-4.43(0.22)$ & $* * *$ & $-0.07(0.07)$ & n.s. \\
\hline & $6 \mathrm{~m}$ & $a+b \cdot$ peat & $-3.99(0.21)$ & $* * *$ & $-0.07(0.06)$ & n.s. \\
\hline & $7 \mathrm{~m}$ & $a+b \cdot$ peat & $-3.58(0.21)$ & $* * *$ & $-0.06(0.06)$ & n.s. \\
\hline & $8 \mathrm{~m}$ & $a+b \cdot$ peat & $-3.18(0.20)$ & $* * *$ & $-0.05(0.06)$ & n.s. \\
\hline & $9 \mathrm{~m}$ & $a+b \cdot$ peat & $-2.78(0.20)$ & $* * *$ & $-0.04(0.06)$ & n.s. \\
\hline & $10 \mathrm{~m}$ & $a+b \cdot$ peat & $-2.38(0.19)$ & $* * *$ & $-0.04(0.06)$ & n.s. \\
\hline & $11 \mathrm{~m}$ & $a+b \cdot$ peat & $-1.99(0.20)$ & $* * *$ & $-0.04(0.06)$ & n.s. \\
\hline & $12 \mathrm{~m}$ & $a+b \cdot$ peat & $-1.61(0.20)$ & $* * *$ & $-0.04(0.06)$ & n.s. \\
\hline \multirow[t]{8}{*}{$\alpha$} & $5 \mathrm{~m}$ & $a+b \cdot$ peat & $2.19(0.06)$ & $* * *$ & $0.02(0.02)$ & n.s. \\
\hline & $6 \mathrm{~m}$ & $a+b \cdot$ peat & $2.14(0.06)$ & $* * *$ & $0.01(0.02)$ & n.s. \\
\hline & $7 \mathrm{~m}$ & $a+b \cdot$ peat & $2.07(0.06)$ & $* * *$ & $0.01(0.02)$ & n.s. \\
\hline & $8 \mathrm{~m}$ & $a+b \cdot$ peat & $2.00(0.05)$ & $* * *$ & $0.01(0.02)$ & n.s. \\
\hline & $9 \mathrm{~m}$ & $a+b \cdot$ peat & $1.91(0.04)$ & $* * *$ & $0.02(0.02)$ & n.s. \\
\hline & $10 \mathrm{~m}$ & $a+b \cdot$ peat & $1.86(0.03)$ & $* * *$ & $0.01(0.01)$ & n.s. \\
\hline & $11 \mathrm{~m}$ & $a+b \cdot$ peat & $1.81(0.03)$ & $* * *$ & $0.00(0.01)$ & n.s. \\
\hline & $12 \mathrm{~m}$ & $a+b \cdot$ peat & $1.74(0.02)$ & $* * *$ & $0.01(0.01)$ & n.s. \\
\hline \multirow[t]{8}{*}{$\theta$} & $5 \mathrm{~m}$ & $a+b \cdot$ peat & $142.6(43.3)$ & $* *$ & $-7.5(13.0)$ & n.s. \\
\hline & $6 \mathrm{~m}$ & $a+b \cdot$ peat & $156.2(34.6)$ & $* * *$ & $-11.0(10.4)$ & n.s. \\
\hline & $7 \mathrm{~m}$ & $a+b \cdot$ peat & $157.8(30.3)$ & $* * *$ & $-9.1(9.1)$ & n.s. \\
\hline & $8 \mathrm{~m}$ & $a+b \cdot$ peat & $175.5(32.5)$ & $* * *$ & $-12.0(9.8)$ & n.s. \\
\hline & $9 \mathrm{~m}$ & $a+b \cdot$ peat & 206.3 (37.9) & $* * *$ & $-15.6(11.4)$ & n.s. \\
\hline & $10 \mathrm{~m}$ & $a+b \cdot$ peat & $312.7(58.5)$ & $* * *$ & $-36.1(17.6)$ & $*$ \\
\hline & $11 \mathrm{~m}$ & $a+b \cdot$ peat & $542.4(125.2)$ & $* * *$ & $-75.3(37.7)$ & n.s. \\
\hline & $12 \mathrm{~m}$ & $a+b \cdot$ peat & $1762.0(679.8)$ & $*$ & $-305.4(204.4)$ & n.s. \\
\hline
\end{tabular}


Table S5. Linear relationship between canopy top height (H99) and canopy gap metrics (mean gap area, $\alpha$ ) in old-growth and logged peat swamp forest

\begin{tabular}{llllll}
\hline & & $\mathrm{a}$ & $\mathrm{b}$ & $\mathrm{R}^{2}$ & $\mathrm{p}$ \\
\hline Old-growth & $\mathrm{H} 99=\mathrm{a}+\mathrm{b} \cdot$ mean gap area & 25.9 & 2.1 & 0.81 & $<0.001$ \\
& $\mathrm{H} 99=\mathrm{a}+\mathrm{b} \cdot \alpha$ & 2.11 & -0.19 & 0.75 & $<0.001$ \\
Logged & $\mathrm{H} 99=\mathrm{a}+\mathrm{b} \cdot$ mean gap area & 25.0 & 0.9 & 0.27 & $<0.001$ \\
& $\mathrm{H} 99=\mathrm{a}+\mathrm{b} \cdot \alpha$ & 2.25 & -0.04 & 0.37 & $<0.001$ \\
\hline
\end{tabular}


Table S6. Effect of cumulative logging pressure index (LPI) and peat depth (peat) on mean gap area at the $2 \mathrm{~m}$ and $3 \mathrm{~m}$ height cross-sections (CS)

\begin{tabular}{lllllll}
\hline & CS & $\mathrm{a}$ & $\mathrm{b}$ & $\mathrm{c}$ & $\mathrm{R}^{2}$ & $\mathrm{p}$ \\
\hline $\mathrm{LPI}=\mathrm{a}+\mathrm{b} \cdot$ peat $+\mathrm{c} \cdot$ mean gap area & $2 \mathrm{~m}$ & 18.2 & -0.4 & 1.7 & 0.14 & $<0.01$ \\
$\mathrm{LPI}=\mathrm{a}+\mathrm{b} \cdot$ peat $+\mathrm{c} \cdot$ mean gap area & $3 \mathrm{~m}$ & 20.5 & -0.5 & 1.8 & 0.27 & $<0.001$ \\
\hline
\end{tabular}




\section{Supplementary figures}

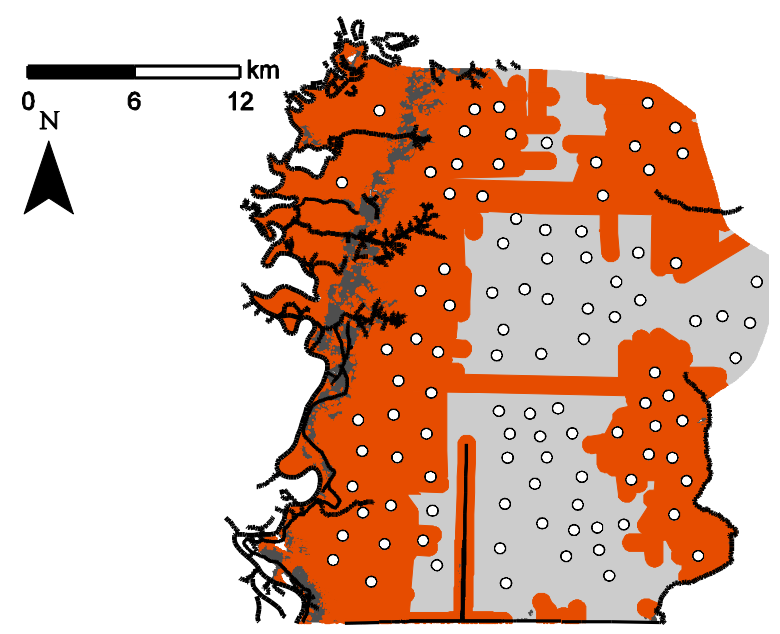

Figure S4. Location of 100 virtual plots in the study area. Distribution of plots in areas affected by pre-2000 concessionary selective logging and subsequent illegal selective logging (red) and in old-growth forest unaffected by logging (grey) as detected by satellite imagery. The centroid point of each plot is shown; the plot size is $1 \times 1 \mathrm{~km}$. No plots were located in areas affected by illegal logging only after the year 2000 (not shown). 


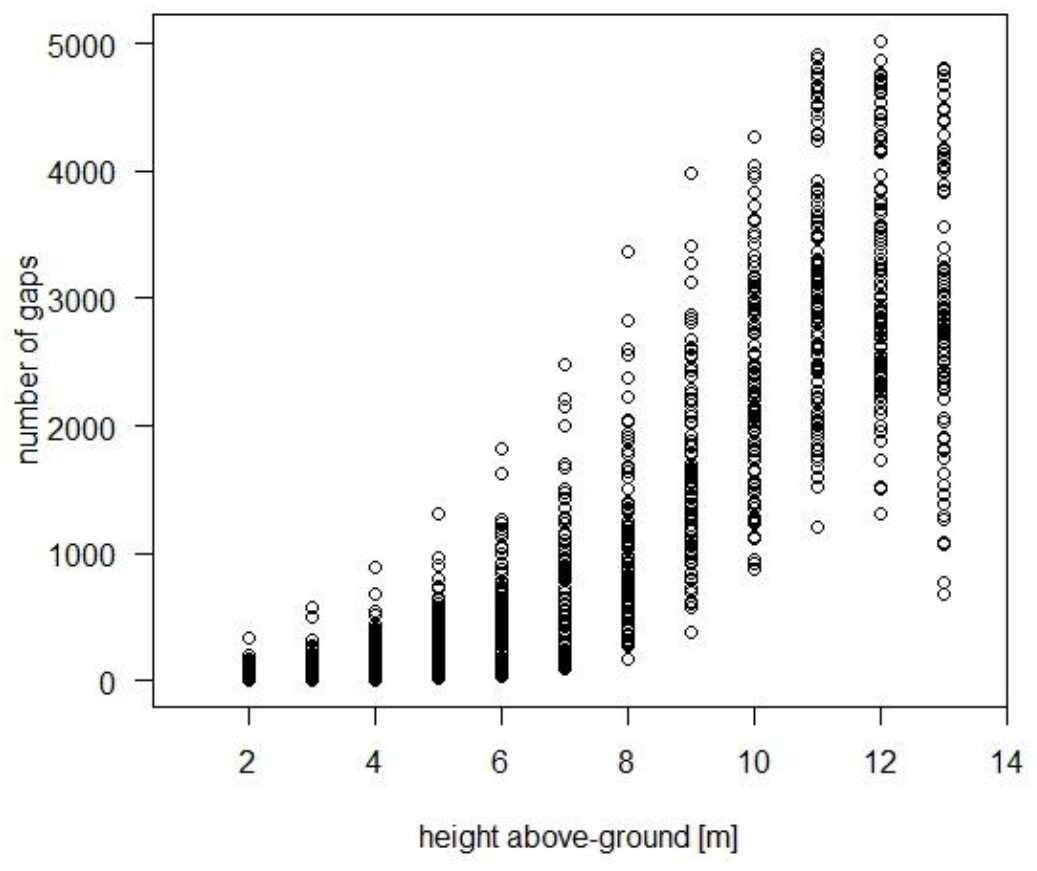

Figure S5. Rationale for stopping gap analysis at the $12 \mathrm{~m}$ height cross-section. Relationship between number of gaps and height layers across the vertical forest profile show a point of inflection at $12 \mathrm{~m}$ above-ground. Above the $12 \mathrm{~m}$ height layer, gaps from singular origins start merging together and the total number of canopy gaps decreases. Each point corresponds to a plot. 

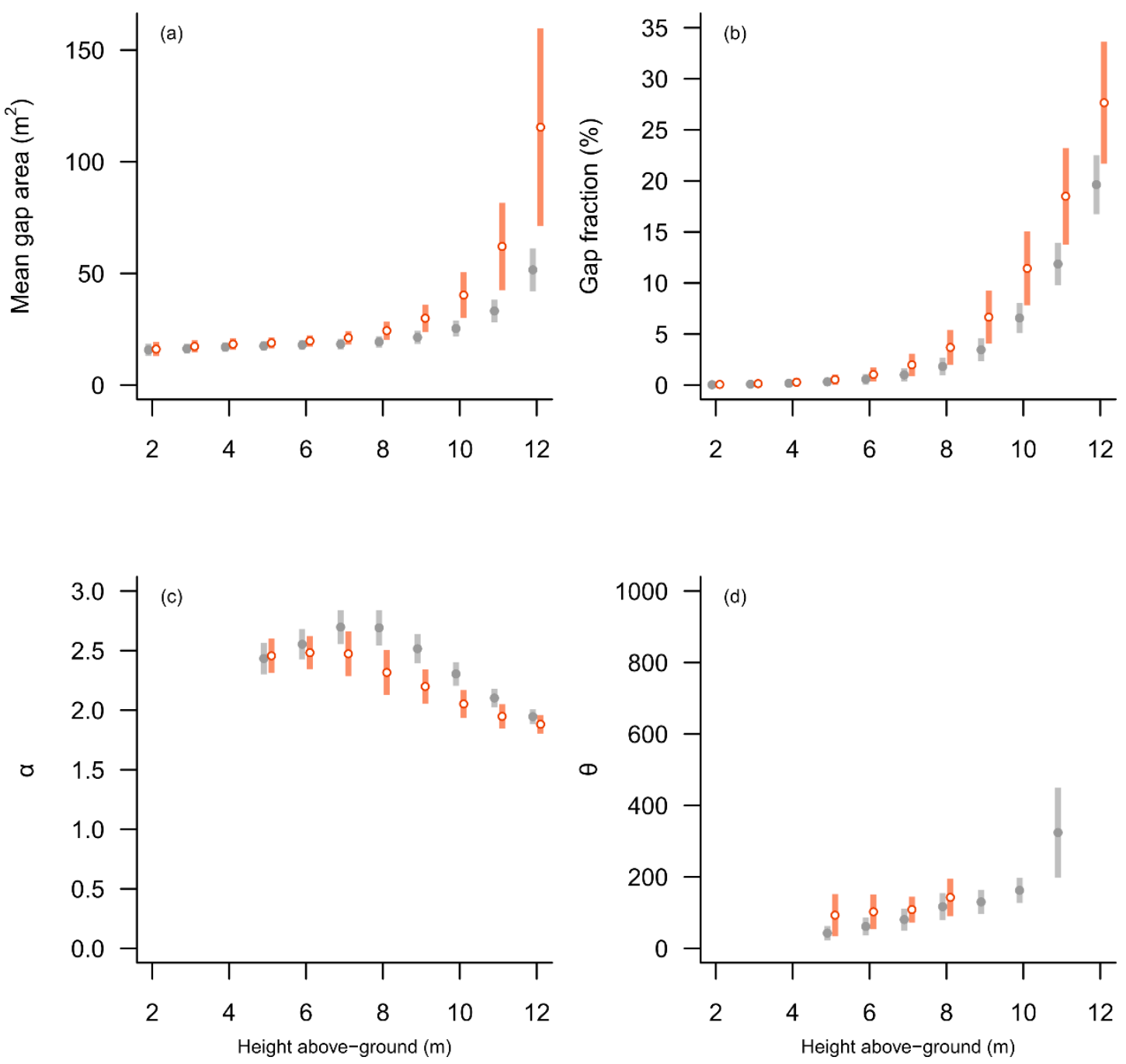

Figure S6. Logging effects with height above ground. Changes in (a) mean gap area, (b) gap fraction, (c) scaling exponent $\alpha$ of the GSFD and (d) transition parameter $\theta$ of the GSFD with height above-ground, going up vertically into the forest profile, in old-growth (grey, closed circles) and logged (red, open circles) peat swamp forest. Parameters $\alpha$ and $\theta$ are only plotted for the cross-sections at which the fitted distribution to the GSFD was valid (cross-sections $\geq$ $5 \mathrm{~m}$ height) and parameters were different from 0 . Averages for sites with peat depth $\geq 6 \mathrm{~m}$ $\left(\mathrm{N}_{\text {old-growth }}=45, \mathrm{~N}_{\text {logged }}=18\right)$ are plotted with $95 \%$ confidence intervals. 


\section{References}

Asner, G. P.: Automated mapping of tropical deforestation and forest degradation: CLASlite, J. Appl. Remote Sens., 3(1), 033543, DOI: 10.1117/1.3223675, 2009.

Asner, G. P., Kellner, J. R., Kennedy-Bowdoin, T., Knapp, D. E., Anderson, C. and Martin, R. E.: Forest canopy gap distributions in the southern peruvian Amazon., PLoS One, 8(4), e60875, DOI: 10.1371/journal.pone.0060875, 2013.

Ballhorn, U., Navratil, P., Jubanski, J. and Siegert, F.: LiDAR survey of the Kalimantan Forests and Climate Partnership (KFCP) project site and EMRP area in Central Kalimantan, Indonesia. [online] Available from: http://issuu.com/iafcp/docs/lidar_721f1a92e190ba (accessed 13/07/2015), 2014.

Bryan, J. E., Shearman, P. L., Asner, G. P., Knapp, D. E., Aoro, G. and Lokes, B.: Extreme differences in forest degradation in Borneo: comparing practices in Sarawak, Sabah, and Brunei., PLoS One, 8(7), e69679, DOI: 10.1371/journal.pone.0069679, 2013.

Englhart, S., Jubanski, J. and Siegert, F.: Quantifying Dynamics in Tropical Peat Swamp Forest Biomass with Multi-Temporal LiDAR Datasets, Remote Sens., 5(5), 2368-2388, 2013.

ESRI: ArcGIS Desktop: Release 10.2. Redlands, CA: Environmental Systems Research Institute, 2013.

Franke, J., Navratil, P., Keuck, V., Peterson, K. and Siegert, F.: Monitoring Fire and Selective Logging Activities in Tropical Peat Swamp Forests, IEEE J. Sel. Top. Appl. Earth Obs. Remote Sens., 5(6), 1811-1820, 2012.

Gaveau, D. L. A., Sloan, S., Molidena, E., Yaen, H., Sheil, D., Abram, N. K., Ancrenaz, M., Nasi, R., Quinones, M., Wielaard, N. and Meijaard, E.: Four Decades of Forest Persistence, Clearance and Logging on Borneo, edited by K. Bawa, PLoS One, 9(7), e101654, DOI: 10.1371/journal.pone.0101654, 2014.

Gelman, A. and Hill, J.: Data Analysis Using Regression and Multilevel/Hierarchical Models., Cambridge University Press., Cambridge., 2007.

Kellner, J. R. and Asner, G. P.: Convergent structural responses of tropical forests to diverse disturbance regimes., Ecol. Lett., 12(9), 887-897, 2009.

Schoenberg, F. P. and Patel, R. D.: Comparison of Pareto and tapered Pareto distributions for environmental phenomena, Eur. Phys. J. Spec. Top., 205(1), 159-166, 2012. 